\title{
EXPERIMENTAL CHANCROID IN MAN
}

\section{Rclative Effectiveness of Various Drugs Tested by Three Methods*}

\author{
By R. R. Willcox, M.D. \\ St. Mary's Hospital, London
}

\section{Introduction}

During 1949, at the invitation of the Government of Southern Rhodesia, the author spent six months in that country undertaking a venereal diseases survey, specifically to determine how new methods of treatment could, consistent with cost and local conditions, be extended to the African native. The project was financed by means of a grant from the Rhodesian State Lottery Trustees. It was found possible, however, to exceed these terms of reference and make a venereal diseases survey of the country as a whole.

On arrival in that country it was evident that, although penicillin was in use in some places for gonorrhoea, this was not the case in the treatment of early syphilis-for which disease a course of four to six weeks, varying upon the clinic, of neoarsphenamine with or without bismuth was being given. Of necessity, also, facilities for dark field examinations, and sometimes serum tests in addition, were often lacking and every case of penile sore, including chancroid which was sometimes unsuspect, was given such treatment without attempts to arrive at a more precise diagnosis.

As it appeared probable that the introduction of penicillin for routine use for early syphilis in the African native would be a more costly method of treatment than the one already in use, it was felt necessary to show that the current method was unsatisfactory. That it was not a thoroughly sound treatment for the syphilitic patient was obvious, although it could be argued that it was not unsatisfactory as a treatment of the masses (the so-called 'public health cure' aimed purely at the eradication of infectious lesions). Moreover, many local doctors were satisfied with the treatment, claiming that the penile sores ultimately healed during the not inconsiderable period that the patients spent in hospital.

* Being the substance of a thesis approved by the University of London for the Doctorate of Medicine examination.
Attention was, therefore, focused on the effects of neo-arsphenamine upon chancroid, for this disease, as is noted in the report, was at once found to be of great prevalence and, in the absence of sufficient diagnostic equipment, all sufferers from this disorder were being treated as for syphilis. It was helpful, therefore, if penicillin was to be recommended for the treatment of syphilis, to show convincingly that the existing treatment was inefficient for chancroid.

The effectiveness of penicillin in the treatment of early syphilis in the African native had also to $\vec{\theta}$ be put to the test under Rhodesian conditions of It was soon show that, if penicillin was used, the syphilitic lesions healed quicker and the time that the patient had to be retained in hospital (admission to hospital of patients with open sores being generally insisted upon) was reduced from upwards of six weeks to only one week. In addition, quite apart from the virtual absence of toxic effects, the ultimate results of penicillin therapy could, according to all published figures, be confidently expected to show an improvement on those obtained by the truncated arsenical and bismuth courses previously in force. Moreover, default, which had precluded all hope of increasing the length of the older regime if patients were to be discharged from hospital, then became of little importance.

Realizing that more adequate diagnostic facilities could only be generally applied after a considerable period of time, it had to be expected that the treatment schedule recommended for early syphilis would, in practice, also be applied to soft sore. Thus it was necessary to ascertain whether the penicillin course was likely to be effective in that disease.

Previously held opinions concerning the efficacy of penicillin on chancroid were contradictory, and the little-published work referred only to small numbers of cases. The reason for this is that the use of penicillin for soft sore is rightly discouraged 
in medically advanced countries, in which a fundamental principle of venereology is properly to exclude syphilis and then adequately to treat and follow each individual proved infected, while those cases not showing positive findings are observed without receiving any drugs which would tend to mask or conceal syphilis which has remained undetected. Sulphonamides are useful for these latter cases, as they are very effective against chancroid, but have no influence on the dark field positive lesions of early syphilis. Such an approach to the problem, the desirability of which cannot be gainsaid, infers not only that there is an adequate provision for proper diagnosis but also that the patients will cooperate in attending the clinic while the tests are being carried out. Neither criterion is met in tropical Africa.

Therefore, if penicillin could be shown also to give an adequate routine cure for chancroid, no great harm would result if this antibiotic is prescribed indiscriminantly for all African cases of genital sore, even in the absence of confirmatory microscopical diagnosis, provided that a curative dose for syphilis is given at the same time. Such an arrangement would be entirely justified, and would represent in many respects an ideal treatment for use in the many rural clinics in which there are no suitable diagnostic aids and the organization of any sort of follow-up is practically impossible.

The collection of adequate data as to the relative effectiveness of various drugs on clinical cases of soft sore, in which syphilis had first been excluded by repeated dark field and appropriate serum tests before treating with penicillin, would have required many months if the numbers so obtained were to be statistically convincing. This would have been impossible to achieve in Southern Rhodesia during the time available for the survey, if the many other aspects concerning venereal disease in the African were to be covered.

However, by experiments employing inoculation of chancroidal matter into relatively small numbers of human volunteers, results were most rapidly obtained ; results which, at the same time, were far more easily controlled than those achieved by the more prolonged method employing clinical cases, had this been feasible.

After a few trials, employing an inoculum of matter taken from chancroidal sores, a change was made to an inoculum of bubo fluid. This material, when injected intradermally, produces a controllable but marked reaction on the forearm of an untreated person, but evokes no such reaction in a patient treated at the time of inoculation with an adequate dose of an effective drug. At first the donors of the bubo fluid were the sole recipients but, once the technique had been perfected in such a way that unpleasant reactions were reduced to a minimum, inoculation into others was also performed. By this means a number of persons $\stackrel{\mathbb{Q}}{\varrho}$ were inoculated simultaneously with the same $C$. material, some being left untreated and others $\vec{F}$ being treated with the different drugs to be tested. $\stackrel{?}{+}$

The experiments were then rechecked using a different method whereby the donors, whose $\frac{\bar{\sigma}}{\bar{c}}$. ability to infect others had first been proved, were $\frac{\sigma}{\sigma}$ themselves then treated with one of the drugs to $\propto$ be tested. At 24-48 hours after the onset of $\%$ treatment a specimen of bubo fluid was again $\overrightarrow{0}$ aspirated and injected intradermally into untreated volunteers, in order to ascertain whether or not $\vec{\omega}$ the treatment given had caused it to lose its $\frac{\sigma}{8}$ virulence. These further experiments yielded $\frac{0}{3}$ almost identical findings with those of the other series and, in all, the results were well defined. $\infty$

As was expected, both streptomycin and the $\omega$ sulphonamides were entirely successful in pre- $\sigma$ venting experimental chancroid. Penicillin was $\overrightarrow{0}$ also successful in the doses given for syphilis, as 0

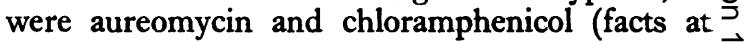
that time unknown to the author but which since $\vec{T}$ have been substantiated in America by work on $\mathbb{P}$ the clinical infection (Greenblatt, et al., 1950)). Neo-arsphenamine, bismuth and antimony proved of little value.

The experiments produced convincing eviden o that the treatment schedules previously in fore were inefficient both for syphilis and chancroic that penicillin administered in doses effective against early syphilis was also effective against soft sore, and that penicillin is a suitable drug for both diseases in localities without diagnostic aids, provided that sulphonamides are given in addition to those patients whose sores fail to heal.

Recommendations based on these observations were accepted and a course of eight daily injections of 600,000 units of procaine penicillin (with or without 2 per cent. aluminium monostearate) has become a standard treatment for the African with early syphilis (Southern Rhodesian Government, 1950). A further recommendation suggested that cases clinically suspicious of chancroid, or patients whose sores were unhealed at the completion of $\frac{}{5}$ treatment, should be given sulphonamides in $\frac{7}{0}$ addition.

Finally, although cross inoculations with chan- N croid have been used on countless occasions in the past, especially for the so-called 'syphilization' $N$ treatment of the previous century, at a time when $\omega$ chancroid was still confused with syphilis in Europe (Abraham, 1944; Lancereux, 1868), it is $\stackrel{0}{=}$ believed that their employment for testing the $\stackrel{\Phi}{\oplus}$ relative value of anti-chancroidal drugs is original. It certainly is an extremely useful method by which to extract controlled data within a short period of time. The experiments helped materially 


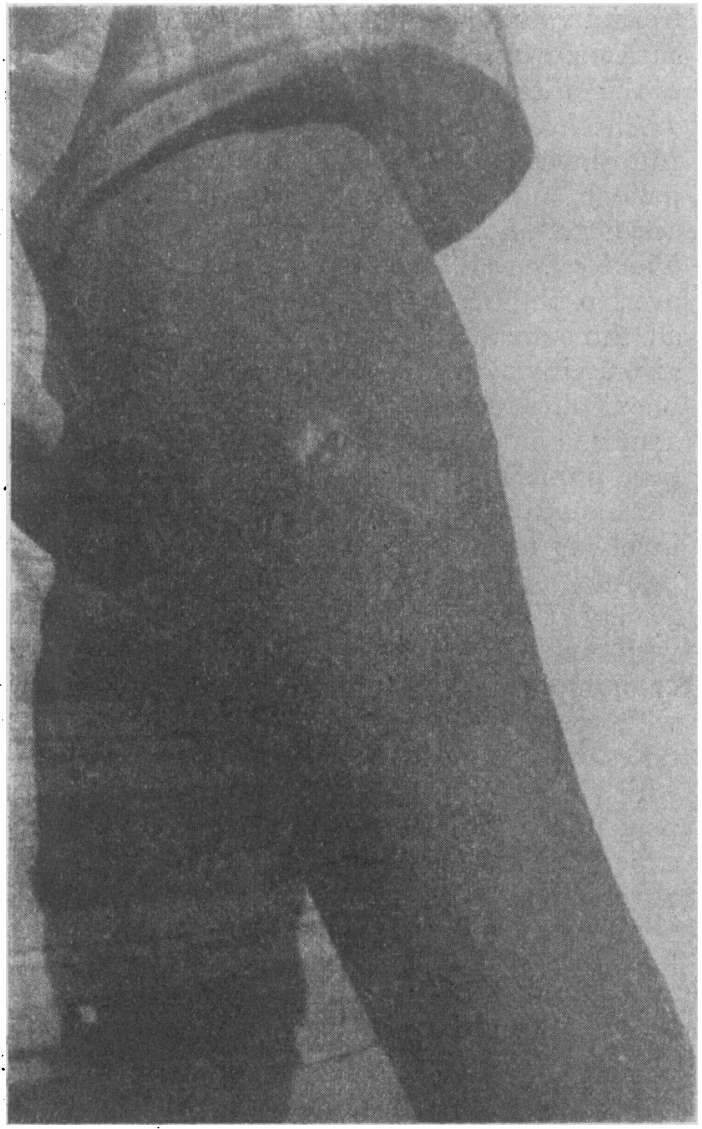

Frg. I

in framing the conclusions of the venereal diseases survey of the African in Southern Rhodesia, which was one of the few, if not the only one undertaken in English-speaking Africa by an independent observer freed from routine duties since that of Lambkin (1908; 19II), which itself led to the development of the medical service in Uganda (Davies, 1947).

\section{Technique}

The effectiveness of different drugs in the experimental infection of chancroid may be compared in various ways. Testing their efficacy against the experimental ulcer once produced has little advantage over treating the clinical infection except, of course, if inoculated subjects are employed, larger numbers of cases may more readily be obtained. Moreover, all volunteers utilized in such experiments are de facto ' takes,' and such an outcome is to be avoided if possible. More satisfactory results, therefore, are achieved by producing conditions in which ' takes' only occur deliberately in the controls and if ineffective drugs

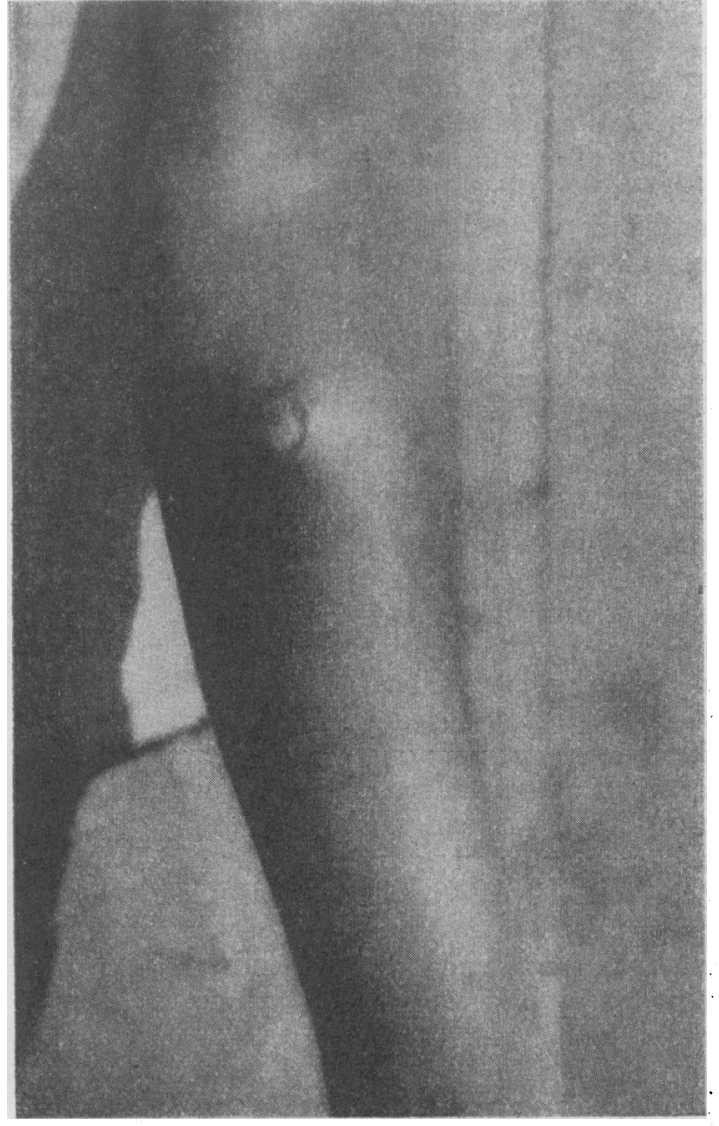

Fig. 2

are administered, but in which no adverse reactions are encountered when effective treatment is given.

First attempts of the author at inducing the experimental infection in humans were made by intradermal injection of material squeezed from the patient's own chancroidal sores, smears from which were shown to contain $H$. ducreyi, into the forearms of two untreated volunteers. One of these inoculations resulted in an angry local ulceration (which responded to treatment), and both reactions were too severe to justify the application of such a method to the substantial numbers required for adequate test to be made.

Trials were next undertaken employing fluid aspirated from chancroidal buboes, and it became evident that, if the amount of fluid injected intradermally into an untreated person is kept as small as $0.05-0.1$ c.c., the reaction is slight and easily controlled. This reaction consists first of an erythema, followed rapidly by the formation of a small tender papule which appears within 24-48 hours, at the end of which time it is firm and raised. Within $48-72$ hours it becomes a pustule 
which, if the patient remains untreated, then proceeds to chancroidal ulceration (Figs. I and 2).

However, if the head of the pustule is removed by a sterilized needle and the patient treated with effective drugs, the subsequent ulceration may be kept to a minimum. It was later found that, if the papule is needled as soon as it is considered pus may be present and if the patient is then treated with effective drugs, the ulcerative stage may be avoided altogether. If the inoculum is greater than 0.05 c.c. the reaction is of the same pattern but the lesions are proportionately larger, and the use of a small inoculum is advisable.

If, however, inoculated persons are treated with effective drugs at the time of inoculation, or the donors with chancroidal buboes whose material is to be used are treated prior to aspiration, such reactions may be avoided completely, and nothing abnormal is observed in the recipient apart from an occasional small, non-tender papule at $24-48$ hours, persisting in a few cases for 72-96 hours. If the drugs used are only partially effective, such papules may persist for a longer time, apparently in a state of suspended animation, only to revive and progress to ulceration once the influence of the drug has been removed. Thus it is considered wise subsequently to treat all persons with persistent papules with a course of drugs of proven value as soon as surveillance is deemed to be complete.

Employing this technique the effectiveness of different drugs may be tested by three methods :

(a) By auto-inoculation of bubo fluid into the arm of the patient himself, treating him with one of the drugs to be tested and noting whether the experimental infection does or does not appear. As a method this is quite satisfactory, but it requires for its use one case of chancroidal bubo for each person injected and it therefore takes time to establish a series of reasonable size.

(b) By hetero-inoculation of bubo fluid from an untreated person into other volunteers, some being given no treatment and others being treated by various drugs from the time of inoculation. Scientifically, this method is perhaps the most satisfactory as, in theory, it is only the response to the call for volunteers which limits both the number of controls and the number of drugs which can be tested on any one day-for only one patient with chancroidal bubo is required for a whole battery of tests.

(c) By hetero-inoculation (and auto-inoculation also) of bubo fluid taken 24 or more hours after the donor has been treated with one of the drugs under consideration. This method is satisfactory, but requires at least one donor for each of the drugs to be tested. It may be controlled before treatment by employing method (b) using un- treated volunteers, but this has the objection that such controls are not inoculated on the same da\$ as the others.

All three methods were used by the autho Auto-inoculation (method a) was given to $33^{\frac{5}{5}}$ patients, nine of whom were untreated and acte\& as controls, not only for this series but for method 용. $b$ and $c$ as well. (There was a certain degree of overlap both as regards controls and donors with all three methods.) The 26 treated cases wer. given either sulpha drugs, penicillin, chloram $\overrightarrow{5}$ phenicol, aureomycin, streptomycin or neoarsphenamine. The detailed results have alreads been published (Willcox, 1950a).

Method $b$ was employed in ten experiment? involving I 44 volunteers. There were 30 controls: but six of these were common to method op Ninety volunteer recipients were treated eithew with sulphathiazole, streptomycin, aureomycin? chloramphenicol, antimony, neo-arsphenamine oP with penicillin -either as oil-beeswax in dail\$s doses, single injections of procaine penicillin $G_{-}$ with aluminium monostearate, or as oral calcium, penicillin. The results obtained in this series of experiments have also been described (Willcox I95ob).

Method $c$ was used for 12 experiments employ ing material from II treated donors who had previously been given either sulphathiazole, streptomycin, aureomycin, chloramphenicol, neos arsphenamine or penicillin-after which bubG fluid was aspirated and injected intradermalle into 75 recipients (Willcox, I950c). Several of the donors had already been used in the experimento involving methods $a$ and $b$ as had many of th $\overrightarrow{\vec{\varepsilon}}$ controls.

The results obtained by the three methods ar complementary and show general agreemen? This paper groups the results of all three sets of experiments, adds some additional data and draws. conclusions on the whole.

\section{The Subjects}

\section{The Donors}

All 35 donors used received auto-inoculation by method $a$. Material taken before treatment from Io was inoculated into II4 others (methoe: $b$ ), and material from II was inoculated into 7 s others after treatment had been given to the donot $(\operatorname{method} c)$, and also into three additional contro before treatment. Bubo fluid from four donory was used in both methods $b$ and $c$.

The donors were all African Negroes wit obvious clinical soft sores which gave negativo findings for syphilis by repeated dark field examination in all but two with mixed infections $\overrightarrow{0}$ these latter patients were used for auto-inoculation only. The buboes were unilateral in all but foư⿱ 
with an equal distribution for left and right ; all were fluctuant. The reports of the Wassermann reactions on 25 of the donors were available and these showed negative results in all but two. Ide and Kahn tests were performed on II with negative results in ro. The Lygranum skin test (for lymphogranuloma venereum) was negative in II of 12 persons tested. Organisms resembling Ducrey's bacillus were found in 70 per cent. of sores examined (see later note) and, of 32 receiving the Dmelcos skin test for chancroid (Ito reaction), 17 were positive, 3 weakly positive and 12 were negative.

\section{The Recipients}

Thirty-five volunteers received auto-inoculation, 114 received hetero-inoculation from untreated donors and 75 others received material from treated donors. Adding three additional controls $(\operatorname{method} c)$, we have a total of 227 individual tests.

All of the recipients were African Negroes with venereal diseases consisting usually of early syphilis, soft sore, or both, chancroid being particularly prevalent in the area in which the experiments were conducted. Of the 227 recipients, the results of the Wassermann reaction were known in 168 and were positive in 51 and negative in 117. The results of the Dmelcos skin tests were positive in 58 , weakly positive in 12 , negative in $14 \mathrm{I}$ and there is no record of 16.

\section{The Experiments}

One hundred and ninety-one persons were inoculated either with their own bubo or sore fluid and then treated by various means (method a) ; with bubo fluid aspirated from another untreated person, the recipient then being treated $(\operatorname{method} b)$; or with bubo fluid taken from a treated person (method $c$ ). There were also $3^{6}$ completely untreated controls. The numbers involved and the various treatments given to those inoculated by the three methods are portrayed in Table $\mathbf{~}$.

\section{Results}

Controls ( 36 cases)

Thirty-four persons received bubo fluid from themselves or from an untreated donor, and two persons received material from their own sores. All were left untreated in order to assess the virulence of the fluid. Of nine untreated persons given their own material there were 'takes' in eight (method $a$ ). Thirty controls were used for method $b$, but six of these were common to the foregoing. Of the remaining 24 controls no less than 2 I showed 'takes.' Although the experiments employing method $c$ had 36 controls the majority were taken from the donors used in methods $a$ and $b$ and there were actually only three additional controls in this series. Of these there was a 'take' in all three.

Thus of a total of 36 controls used in the entire investigation there were "takes" in 32. Theo findings of the Dmelcos skin tests of the controls were as follows : positive 8 , weakly positive 1 , negative 26 , no record $I$. The results of the Wassermann tests were : positive 5 , negative 27 and no record 4. Of the four controls who failed

TABle I

Numbers of Recipients Inoculated and Nature of Treatment Given

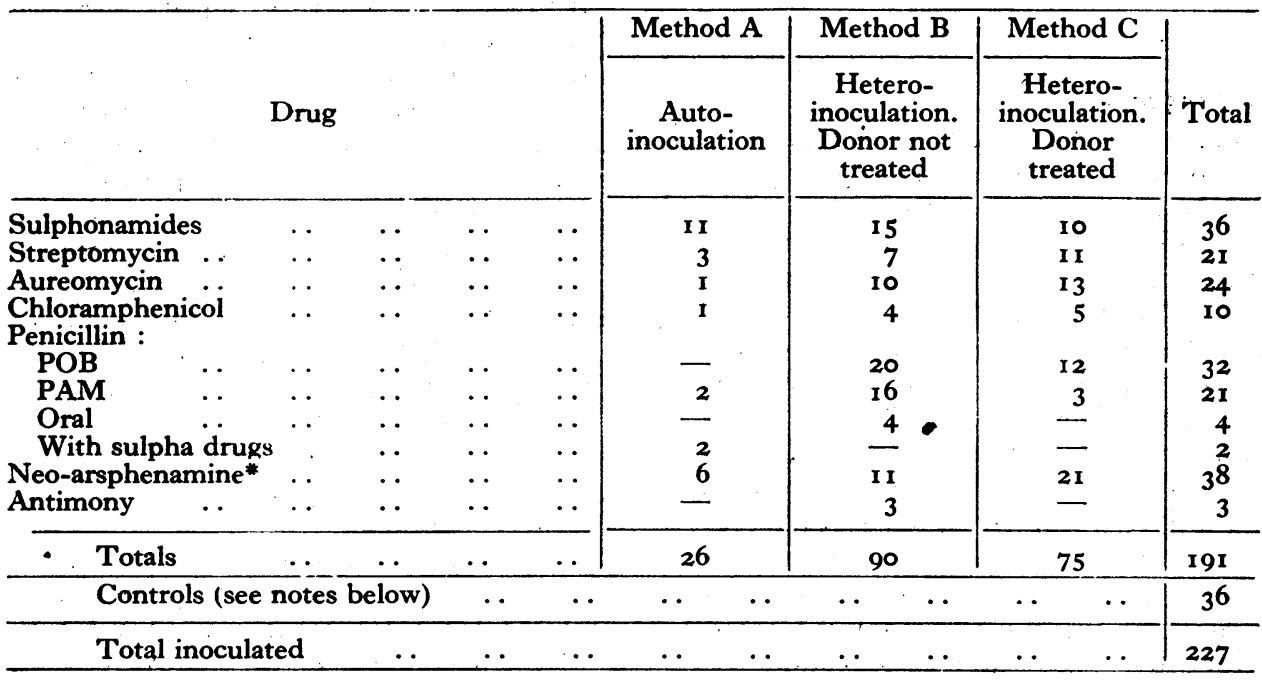

* Three of these patients received bismuth also. 
to 'take,' the Wassermann reaction was negative in all and the Dmelcos skin test was negative in three with no record in one.

\section{Sulphonamides ( 36 cases)}

Of 11 persons receiving auto-inoculation during a 5-7-day course of sulphathiazole, sulphadiazine or ' prontosil,' only one developed a 'take.' Of ten recipients inoculated with material taken from three of these persons $24-72$ hours after treatment had been commenced with $4 \mathrm{~g}$. sulphathiazole daily, there were 'takes' in none. Of 15 other volunteers, treated with sulpha drugs after inoculation of material of proved virulence from four untreated donors, there were no definite ' takes,' but two doubtful reactions which subsided as the course of sulpha drugs was continued. Thus of the $3^{6}$ recipients in the sulphonamide-treated group there was a 'take' in only one and there were two doubtful reactors: Thus the effectiveness of sulphonamide drugs in preventing experimental chancroid is evident.

\section{Streptomycin ( 2 I cases)}

Of ten persons treated with $1.5-6.0 \mathrm{~g}$. of streptomycin given over 2-5 days, and inoculated with bubo fluid of proved virulence, three by autoinoculation and seven by hetero-inoculation, there were 'takes' in none, although one showed a persistent non-tender papule at 96 hours. Material from two donors treated as above was inoculated 24-72 hours after treatment had commenced into eleven others with negative results in all, although one patient showed a persistent non-tender papule which was aspirated on the sixth day and found not to contain pus. Thus streptomycin also proved effective in aborting the experimental infection.

\section{Aureomycin (24 cases)}

One person receiving auto-inoculation and being treated with $2,000 \mathrm{mg}$. aureomycin orally over three days developed a delayed 'take' with ulcer formation at seven days. Material from the bubo of this patient was inoculated into 13 others 24-120 hours after treatment had commenced and there was a ' take' only in one (inoculated at 24 hours). In addition, hetero-inoculations with material of proved virulence, taken from four untreated donors, were performed on ten persons who were then given 500-1,250 mgm. of aureomycin orally over 2-4 days. There was a 'take' in none.

Aureomycin thus proved effective in preventing the experimental infection, although possibly slightly less so than the sulphonamides or. streptomycin.

\section{Chloramphenicol (10 cases)}

One person, receiving auto-inoculation and treated with $250 \mathrm{mg}$. of chloromycetin oralty three times a day for three days, showed a locgi 1 bump at 48 hours which was not tender bift persisted until 120 hours, when it was needled but found not to contain pus. Four persons receiving hetero-inoculations of material of prove virulence from three untreated donors, the recipients then each being given 7-12 capsules of $250 \mathrm{mgm}$. of chloramphenicol orally over $3 \overrightarrow{5}$ days, all failed to show a 'take.' Bubo fluid from the patient receiving auto-inoculation was inocis lated into five others, 24-48 hours after treatmeat of the donor had commenced, with a 'take' none. Thus chloramphenicol also possesses prof phylactic properties against the experimentâ chancroidal infection.

\section{Penicillin}

Four methods of penicillin administration were tested : (a) Eight daily injections of penicillin in oil beeswax (POB) ; (b) The same in combinatiom with sulphonamides; (c) Single injections of procaine penicillin in oil with 2 per cent. alu minium monostearate (PAM); and (d) Orat penicillin. The results show that, in adeqgates doses, penicillin is an efficient prophylactic agann chancroid but in inadequate doses it is Gat Whether a given dosage is or is not adequate depends on the method of administration, and the various methods employed are, therefore, cons sidered separately.

Penicillin $G$ in Oil-Beeswax (32 cases). Twent persons were inoculated with bubo fluid of proved virulence while under treatment with eight daik injections of 600,000 units of penicillin $G$ in oi beeswax ; I4 had received $0-2$ doses and six $3-5$ doses at the time of inoculation. There we definite ' takes' in none, although three volunteers exhibited non-tender papules persistent at 96-123 hours after inoculation, and who had received two, three and four doses of penicillin respective? at the time of inoculation. Another person who was treated with considerable doses of ne ${ }^{2}$ arsphenamine without any loss of virulence of tle bubo fluid (as evidenced by the results of heter inoculation into others) was then given eight daiffir injections of 600,000 units of penicillin in oit beeswax. Material from this case taken at 48-78 hours after the commencement of penicillin treatment, and inoculated into 12 others, produced a ' take' in none.

Thus eight daily injections of 600,000 units penicillin $G$ in oil-beeswax proved efficient $\overrightarrow{5}$ anti-chancroidal. It may be noted here that on of the volunteers in the control series had cont pleted such an eight-day course two days prior 
TABLE 2

SUMmary of 'Takes' by all Methods

\begin{tabular}{|c|c|c|c|c|c|c|c|}
\hline \multicolumn{4}{|c|}{ Treatment } & $\begin{array}{c}\text { Tatal } \\
\text { persons } \\
\text { inoculated }\end{array}$ & 'Takes' & No 'takes' & \% 'takes' \\
\hline $\begin{array}{l}\text { Controls } \\
\text { Sulphonamides } \\
\text { Streptomycin } \\
\text { Aureomycin } \\
\text { Chloramphenicol } \\
\text { Penicillin : } \\
\text { POB alone } \\
\text { POB with sulpha } \\
\text { PAM } \quad . \\
\text { Oral } \quad \ldots \\
\text { Neo-arsphenamine } \\
\text { (Bismuth) } \quad . \\
\text { Antimony } \quad \ldots\end{array}$ & $\begin{array}{l}\cdots \\
\cdots \\
\cdots \\
\cdots \\
\cdots \\
\cdots \\
\cdots \\
\cdots\end{array}$ & $\begin{array}{l}\ldots \\
\ldots \\
\ldots \\
\cdots \\
\ldots \\
\ldots \\
\cdots \\
\cdots \\
\cdots\end{array}$ & $\begin{array}{l}\cdots \\
\cdots \\
\cdots \\
\cdots \\
\cdots \\
\cdots \\
\cdots \\
\cdots \\
\cdots \\
\cdots\end{array}$ & $\begin{array}{r}36 \\
36 \\
21 \\
24 \\
10 \\
\\
32 \\
2 \\
21 \\
4 \\
38 \\
(3) \\
3\end{array}$ & $\begin{array}{r}32 \\
1 \\
0 \\
2 \\
0 \\
0 \\
0 \\
9 \\
1 \\
25 \\
(2) \\
3\end{array}$ & $\begin{array}{r}4 \\
35 \\
21 \\
22 \\
10 \\
32 \\
2 \\
2 \\
12 \\
3 \\
13 \\
(1) \\
0\end{array}$ & $\begin{array}{r}88.9 \\
2.8 \\
\text { Nil } \\
8.3 \\
\text { Nil } \\
\\
\text { Nil } \\
\text { Nil } \\
42.8 \\
25.0 \\
65.8 \\
66.6 \\
100.0\end{array}$ \\
\hline & & & & 227 & 73 & 154 & \\
\hline
\end{tabular}

inoculation. This case showed a 'take,' but it was very much delayed in its appearance, frank ulceration being discovered 35 days later.

Penicillin and Sulphonamide Drugs Combined (2 cases). Two volunteers, treated with eight daily injections of 600,000 units of penicillin $G$ in oilbeeswax, plus $4 \mathrm{~g}$. of sulphathiazole daily, also received auto-inoculations. Both failed to show a ' take.'

Procaine Penicillin with Aluminium Monostearate (2 I cases). The so-called 'single-shot' treatment of syphilis, employing one intramuscular injection of 2.4 mega units of procaine penicillin $G$ in oil with 2 per cent. aluminium monostearate ( 1.2 mega units in each buttock) was tested as to its powers of aborting experimental chancroid at varying time intervals after administration.

Two persons received auto-inoculation; one who was given the penicillin injection simultaneously with inoculation showed ' no take,' but another, receiving the inoculation six days after the penicillin injection, did so. Fluid from the latter case, aspirated after treatment, was inoculated into two others without result, and bubo material from the former was inoculated into one other 24 hours after being given penicillin, also without result.

Hetero-inoculations with material of previously known virulence were performed on 16 volunteers. Of eight inoculated $0-4$ days after penicillin had been given to the donor there were 'takes' in only two, but of eight inoculated $5-8$ days afterwards there were 'takes' in no less than six. One of those, who was inoculated five days after receiving penicillin, did not 'take' at once, but a large ulcer had appeared when the patient was seen 35 days later.
These results shows that single injections of 2.4 mega units of procaine penicillin with 2 per cent. aluminium monostearate given simultaneously with inoculation of bubo fluid offers fair protection against the experimental infection. Of ten persons concerning whom the inoculations took place within $0-4$ days after being given such a dose of penicillin there were only two 'takes,' while of eleven persons receiving inoculations 5-8 days after injection ' takes' were noted in no less than seven.

Oral Penicillin (4 cases). Four persons given hetero-inoculation of material of proved virulence received 400,000-600,000 units of calcium penicillin orally each day for 3-4 days. There was a ' take' in one.

Thus when there was an adequate serum concentration of penicillin there was an effective suppression of the experimental infection.

\section{Neo-arsphenamine ( 38 cases)}

The tests with neo-arsphenamine provided the raison d'être for the investigation. In many countries of the world, even today, neo-arsphenamine is still the drug in routine use for syphilis, and 'syphilis' is often taken to mean any case of penile sore. In the area in which these experiments were undertaken the drug was generally employed in such a manner and, although chinical chancroid was very prevalent, the local medical officers frequently stated that all sores so treated healed, albeit slowly, and there was not at the time any widespread disatisfaction with its action, which had not then been thrown into relief by the more dramatic effects of penicillin. Thus if neoarsphenamine was actually effective in the treatment of soft sore of the African, many of the objections to the use of this drug in proper doses 
for all cases of penile sore became invalid, and such treatment could not be criticized on therapeutic grounds alone, apart from the considerations of default, toxicity and economy of time spent in hospital. It was, therefore, considered important that proper evidence should be secured so as to be able to refute any possible suggestion that the use of neo-arsphenamine for soft sore had anything to recommend it over the use of more modern drugs as the sulphonamides and antibiotics. The results obtained by the experiments were completely effective in so doing, although, in fact, the demonstration of the success of penicillin therapy for early syphilis in the African native was so convincing that it never became necessary to present the experimental data.

Employing auto-inoculation into three persons receiving up to $0.9 \mathrm{~g}$. of neo-arsphenamine during the week prior to inoculation, and continuing afterwards, and into three other persons commencing treatment simultaneously (one of whom had x.2 g. during the ensuing six days), there were four "takes" in" the six volunteers inoculated. Bubo fluid from one of these not showing a ' take' on himself was inoculated into another 24 hours after receiving a neo-arsphenamine injection -also with no result. However, the patient receiving $1.2 \mathrm{~g}$. in less than a week had further specimens of bubo fluid taken on different days 24-168 hours after the onset of treatment and these were inoculated into 20 others with no less than 15 ' takes.' Actually there were 'takes' in three out of four persons inoculated with this bubo fluid on the seventh day after treatment, by which time the virulence of the fluid had evidently not even been reduced. This donor was then treated with eight daily injections of 600,000 units of penicillin $G$ in oil-beeswax and, as has already been described, further specimens were aspirated 48-72 hours later and inoculated into 12 persons with a subsequent 'take' in none. In addition, hetero-inoculations from untreated donors of proved virulence were made into eleven recipients who were all treated with neo-arsphenamine. Three had already received before inoculation I-6 weekly doses of $0.45^{-0.6} \mathrm{~g}$. of neo-arsphenamine (with 0.2 g. of bismuth in addition), and in eight the arsenical treatment commenced simultaneously with inoculation and consisted of $0.45-0.9 \mathrm{~g}$. of neo-arsphenamine given over 24-72 hours. No less than six showed a ' take'-frequently those persons receiving the larger amounts.

Neo-arsphenamine thus proved a most inefficient prophylactic against the experimental chancroidal infection.

Bismuth (3 cases)

Three of the persons receiving neo-arsphen- amine prior to inoculation of bubo fluid from an untreated donor had had, respectively, one, thre and six weekly injections of $0.2 \mathrm{~g}$. of bismuth in addition. These persons, therefore, carried a smaill depôt of bismuth in their buttocks. However, in spite of this, 'takes' were noted in two and thus bismuth likew'se proved an ineffectual prophylactic을

TABle 3

'TAKes' BY Methods

\begin{tabular}{|c|c|c|c|c|c|}
\hline & & $\begin{array}{c}\text { Method } \\
\text { A }\end{array}$ & $\begin{array}{c}\text { Method } \\
\text { B }\end{array}$ & $\begin{array}{c}\text { Method } \\
\text { C }\end{array}$ & Totad \\
\hline $\begin{array}{l}\text { 'Takes' } \\
\text { No'takes' }\end{array}$ & $\begin{array}{l}\cdots \\
\cdots\end{array}$ & $\begin{array}{l}15 \\
20\end{array}$ & $\begin{array}{l}39 \\
75\end{array}$ & $\begin{array}{l}19 \\
59\end{array}$ & $\begin{array}{r}73{ }^{\circ} \\
15 \text { 否 }\end{array}$ \\
\hline Total ... & $\ldots$ & 35 & I 14 & 78 & \\
\hline
\end{tabular}

Antimony (3 cases)

के

Material of proved virulence from one donor was inoculated into one volunteer receiving daify injections of 2 c.c. of antiomaline at the time of the third dose, and into two other persons receiving $I \mathrm{~g}$. of sodium antimony tartrate on alternatis days. 'Takes' were noted in all three. Antimon? likewise is not considered an effective prophylactie

\section{Summary and Conclusions}

(I) The effectiveness of different drugs aborting the experimental infection of chanctidt in man was tested by three methods :

(a) By intradermal auto-inoculation of bubs fluid and treating the recipient with one of the drugs to be tested simultaneously with inoculag tion ;

(b) By hetero-inoculation of material from the untreated donor ; and

(c) By hetero-inoculation from the treateg donor.

(2) Material from chancroidal sores was emb ployed as the inoculum in two cases, but the severe reactions which followed its use promptea a change to bubo fluid, after which, provided thit the quantities of this inoculum were kept sma ( 0.05 c.c.), the reactions observed were easib. controlled.

(3) Some 227 persons were inoculated, $35 \frac{}{B}$ auto-inoculation, II4 by. hetero-inoculation material from ten untreated donors, and 78 others in a series employing hetero-inoculation material from in treated donors; 36 volunteets acted as controls and there were 'takes' in 32 . O

(4) The drugs tested included various sulphos amides, steptomycin, aureomycin, chloramphen $E_{5}$ col, neo-arsphenamine and antimony. Penicill $G$ was also used, either as daily injections of aw oil-beeswax preparation (alone or in combinatio with sulphonamides) as a single injection of 2.9 
mega units of procaine penicillin $G$ with aluminium monostearate, or as oral calcium penicillin.

(5) Sulphonamides, streptomycin and chloramphenicol proved entirely effective in preventing the experimental infection. Aureomycin was also successful, but not in all cases.

(6) Neo-arsphenamine, bismuth and antimony, on the other hand, proved ineffective in preventing experimental chancroid.

(7) Penicillin in high and sustained dosage, as when given in the form of daily injections of an oil-beeswax mixture, was also completely successful. When the inoculation was given near to the time of injection a single dose of 2.4 mega units of procaine penicillin with 2 per cent. aluminium monostearate was fairly but not completely successful, but the effectiveness of this treatment rapidly deteriorated as the time interval between injection and inoculation was lengthened.

(8) The 73 'takes' occurred irrespective of the results of the Wassermann reactions or Dmelcos skin tests of the recipients, and there was no evidence to suggest that the presence or absence of a positive Dmelcos (Ito) test indicated any form of increased immunity against the experimental infection.

(9) Seventy-five per cent. of the 'takes' occurred within 72 hours and, in most cases, those noted as occurring later could have been anticipated at this time. In five instances the 'take' was delayed for a week or longer in patients showing persistent papules ; three of these showed late ulceration. As it was evident in such cases tnat the infection might be dormant, under temporary influence of the drug that was being tested, only to reactivate as its influence was removed, it was later considered advisable to treat all patients with persistent papules with an effective drug as soon as surveillance had been concluded.

(10) Both aureomycin and chloramphenicol were shown to have a definite action in preventing experimental chancroid in man. It is of interest to note, on this account, that Wetherbee, et al. (1949) reported that aureomycin exerts only a transient inhibitory effect on $H$. ducreyi in vitro and that "streptomycin is possibly the only (antibiotic) agent with therapeutic possibilities in this disease:' Since then Zheutlin and Robinson (1950) and Greenblatt, et al. (1950) have reported success in the clinical infection.

(II) It is noted that aureomycin and chloramphenicol both have some action upon all of the common venereal diseases, namely soft sore ; syphilis (O'Leary, et al., 1948; Irgang and Alexander, 1948; and Willcox, 1949); gonorrhoea (Collins, et al., 1949) ; granuloma inguinale (Greenblatt, et al., 1948) ; lymphogranuloma venereum (Wright, et al., 1948); and also non- specific urethritis (Finland, et al., 1948; Willcox ڤ and Findlay, 1949). It would seem propitious, $\frac{3}{\infty}$ therefore, to employ these drugs on a large scale $\stackrel{\varrho}{\complement}$ in experiments on systemic prophylaxiș.

(12) The technique of employing intradermal $\overrightarrow{\vec{\omega}}$ inoculation of bubo fluid into volunteers treated $\overrightarrow{0}$ with various drugs gave rapid and clear-cut results $\overline{0}$ in a far shorter time than if a comparable number $\overline{\bar{\omega}}$. of clinical cases had been collected and treated. $\overparen{\nabla}$ Moreover, the experimental condition under treatment is more standardized than is the clinical is case of soft sore.

(13) The results of these experiments gave $\overrightarrow{\vec{\omega}}$ helpful information as to the dose of penicillin $\stackrel{\omega}{\sigma}$ which should be recommended for the treatment $\overline{8}$ of African syphilis in circumstances in which no 3 proper diagnosis, confirmed by dark field and i serological examination, is possible, and in which, $\underset{\omega}{\omega}$ therefore, chancroid would in practice be treated $\frac{\omega}{\sigma}$ as for syphilis.

(14) The conclusions were put to the test clinically. Eight daily injections of 600,000 units 을 of procaine penicillin $G$, with or without 2 per cent. aluminium monostearate, or of penicillin in 7 oil-beeswax, gave entirely satisfactory results in $\frac{0}{7}$ both early syphilis and chancroid (i.e. on nearly all patients with genital sores). This schedule was, therefore, recommended as the standard for earlo $\vec{\phi}$ syphilis. The recommendation was accepted an has since been implemented (Southern Rhodesia Government, 1950).

(15) On paper the employment of a single injection of 2.4 mega units of procaine penicillin with 2 per cent. aluminium monostearate (PAM), which dose will give a detectable serum level for 7-9 days, has much to recommend it as it is most convenient for isolated rural African clinics visited only occasionally by a doctor.

Such treatment has been tried in the United States of America (Thomas, et al., 1949), and a recent appraisal by Bauer, et al. (1950) suggests that the results so far are not significantly inferior to those obtained by the eight-day course. After a personal trial of this method it was recommended in the report that it be tried experimentally.

Of 19 patients with soft sore, personally treated in Southern Rhodesia with single injections of 2.4 mega units of procaine penicillin $G$ with 2 per cent. aluminium monostearate (syphilis being or properly excluded), only three required additional $N$ treatment with sulphonamides. Eighty suspected $\underset{\mathrm{N}}{\mathrm{N}}$ syphilitics in the same series of consecutive $O$ patients, proved by dark field in $3 \circ$ and suggested by serum tests in 22 others, many of whom had $\frac{0}{\mathscr{D}}$ mixed infections with chancroid, received single $\stackrel{\odot}{+}$ injections of 2.4 mega units of procaine penicillin $T$ with 2 per cent aluminium monostearate. Only 12 required additional treatment (Willcox, 1950d). 
(16) It is considered that, if single injection methods are used in the treatment of syphilis in medically undeveloped areas, a dose of not less than 2.4 mega units of procaine penicillin $G$ with 2 per cent. aluminium monostearate should be employed.

Although it has been suggested that syphilis might actually be cured with even a lesser amount, for many years yet chancroid will, in many of the more primitive countries of the world, continue to be treated in the same manner as early syphilis.气 As an adequate serum level, sustained for some 3 days, is necessary to cure soft sore, it is, therefore, asserted that the dose given for syphilis should not be less than 2.4 mega units.

(I7) It is re-emphasized that the recommenda $\frac{\text { ? }}{7}$ tions made are applicable only to places like tropicaE Africa and are not necessarily suited to localen conditions in Europe or America.

\section{BIBLIOGRAPHY}

ABRAHAM, J. J. (1944), Brit. F. Surg., 32, 236.

BAUER, T. J., USILTON, L. J., PRICE, E. V. (1950), f. vener. Dis. Inform., 31, 65 .

COLLINS, H. S. TROUSDALE, H., KAISER, T. F., REGAN, F. G., and FINLAND, M. (1949), Amer. $\mathcal{F}$. Syph., 33, 263.

DAVIES, J. N. F. (1947), East African med. F., 24, 437.

FINLAND, M., COLLINS, H. S., and PAINE, T. F. (1948), 7. Amer. med. Ass., 138, 946.

GREENBLATT, R. B., DIENST, R. B., CHEN, C. H., and WEST, R. M. (1948), South. med. F., 4I, 1121 .

GREENBLATT, R. B., WAMMOCK, V. S., CHEN, C. H., DIENST, R. B., and WEST, R. M. (1950), F. vener. Dis. Inform., 3r, 45.

IRGANG, S., and ALEXANDER, E. R. (1948), Harlem Hosp. Bull., 1, 91.

LANCEREUX, E. (1868), $A$ Treatise on Syphilis, New Sydenham Society, London.

LAMBKIN, F. J. (1908), F. Roy. Army med. Corps., 2, 149.

LAMBKIN, F. J. (19i1), A System of Syphilis, Oxford Medical Publications, 2, 329.

MOORE, J. E. (1947), 'A Modern Treatment of Syphilis,' G. C. Thomas, Illinois.
O'LEARY, P. A., KIERLAND, R. R., and HERRELL, W. E:(1948), Proc. Mayo Clinic., 23, 574.

SOUTHERN RHODESIAN GOVERNMENT (1950), 'De-W partment of Health Circular No. 45.

THOMAS, E. W., REIN, C. R., and KITCHEN, D. K. (1949) Amer. F. Syph., 33, 523.

WETHERBEE, D. G., HENKE, M. A. ANDERSON, N. I. , and PULASKI, E. J. (1949), Amer. $\mathcal{F}$. Syph., 33, 462.

WILLCOX, R. R. (1949), Report of a Venereal Diseases Survey of the African in Southern Rhodesia, Southern Rhodesian Govern ment.

WILLCOX, R. R. (1949), Brit. med. $\dot{f}$., ii, 1076.

WILLCOX, R. R. (1950a), Amer. F. Syph., 34, 378.

WILLCOX, R. R. (1950b), Arch. Dermat. and Syph Chicago, 62 533.

WILLCOX, R. R. (1950c), Brit. F. vener. Dis., 26, 131.

WILLCOX, R. R. (1950d), F. Roy. Army med. Corps., 94, 126. WILLCOX, R. R., and FINDLAY, G. M. (1949), Brit. med. $\mathcal{F}$. D ii, 257 .

WRIGHT, L T SANDERS, M. LOGAN, M. A., PRIGOTC A., and HILL, L. M. (1948), Y. Amer. med. Ass., 138, 408. ZHEUTLIN, H. E. C., and ROBINSON, R: C..V. (1950), Aper. F. Syph., 34, 71.

\section{RUTHIN CASTLE, NORTH WALES}

A Clinic for the diagnosis and treatment of Internal Diseases (except Mental or Infectious Diseases). The Clinic is provided with a staff of doctors, technicians and nurses.

The surroundings are beautiful. The climate is mild. There is central heating throughout. The annual rainfall is 30.5 inches, that is, less than the average for England.

The Fees are inclusive and vary according to the room occupied.

For particulars apply to THE SECRETARY, Ruthin Castle, North Wales.

Telegrams: Castle, Ruthin.

Telephone: Ruthin 66. 